ORIGINAL ARTICLE

AFRICAN JOURNAL OF CLINICAL AND EXPERIMENT AL MICROBIOLOGY SEPTEMBER 2008 ISBN 1595-689X VOL 9 No 3

AJCEM/200786/20824

-http://www.ajol.info/journals/ajcem

COPYRIGHT 2008

AFR. J. CLN. EXPER. MICROBIOL. 9 (3): 157-165

\title{
MICROBIAL SPECTRUM OF PELVIC INFLAMATORY DISEASES IN NGURU, NIGERIA
}

\author{
Okon, K.O., Ayilara R., Bello K., Uba A., Aniesona T. A.
}

\begin{abstract}
Department of Medical Microbiology, University of Maiduguri Teaching Hospital Maiduguri. Pathology/Obstetritic \& Gynecology department, Federal Medical Centre Nguru, Yobe State. Department of Biological Sciences, Abubakar Rafawa Balewa University, Bauchi Department of Veterinary Microbiology and Parasitology, University of Maiduguri
\end{abstract}

Corresponding Address: Okon, K.O. Department of Medical Microbiology University of Maiduguri Teaching Hospital P.M.B. 1414 Maiduguri. E-mail: okon_kenneth@yahoo.com

\begin{abstract}
Pelvic inflammatory diseases, a leading gynecological problem worldwide, are associated with socio-economic and psychological costs. A retrospective study of 1350 high vaginal swabs analyzed between Jan-Dec. 2005, showed that $845(62.8 \%)$ were positive for 9 microorganisms by culture/or wet preparation. Microbial growth was found in 645 (76.3\%) cases. Polymicrobial growth was found in $90(10.7 \%)$, fungal growth in $110(13.0 \%)$ cases, and 3(0.4\%) yielded anaerobic growth. Staphylococcus aureus accounted for $355(42.0 \%)$ cases, followed by Escherichia coli 190 (22.5\%), Trichomonas vaginalis 100 (11.8\%) Candida spp and Neisseria gonorrhoeae 70 (8.3) and the least, Pseudomonas spp $5(0.6 \%)$ Microbial-associated infection was prominent in the group 21-30 years old $(46.6 \%)$ and $31-40(23.9 \%)$ years respectively. Antibiotic susceptibility pattern showed that mean susceptibility greater than $50 \%$ were recorded with ofloxacin $80 \%$, ceftazidime $80 \%$, rifampicin $81.9 \%$ compared to mean susceptibility less that $50 \%$ recorded with trimethoprim-sulthamethoxazole $34.7 \%$, and ampicillin $26.1 \%$.
\end{abstract}

In conclusion, the reported microbial-associated infection in PID with a prevalence of $62.8 \%$ is of public health importance. Early diagnosis of causative agents and prompt institution of chemotherapeutic agents will help to prevent clinical complications that are expensive to treat.

Keywords: pelvic inflammatory diseases, microorganisms, antibiotic susceptibility.

\section{INTRODUCTION}

Pelvic inflammatory disease (PID), is an infection of the upper genital tract in women that include endometritis, parametritis, salpingitis, oophoritis, tubo-ovarian abscess and peritonitis $(1,2)$. It accounts for $5-20 \%$ of hospital admissions for gynecological problems in general/gynecological clinics worldwide (3). In USA, infertility that affects approximately 10$15 \%$ of all couples attribute tubal damage due to pelvic infection $(4,5)$. Clinical presentation varies in severity, and ranges from sub clinical, asymptomatic infections exerting medical and psychological cost that include chronic pelvic pain, ectopic pregnancy and infertility (1). It has been associated with increase risk of ovarian cancer6-8. The pathogenesis is complex interaction of genetic, immunological and bacterial virulence factors (9). 
The prevalence and incidence of PID varies greatly, because of significant misdiagnosed/or unreported cases. In developed countries, annual incidence of PID increased in women aged 15-45 years, with peak of infection in 20-24 years (10).

Polymicrobial agents are associated and initiated pathogenesis of PID, particularly in presence of facultative aerobic and anaerobic bacterial isolates (11-14), with Niesseria. Gonorrhoea and Chlamudia tracomatis as leading pathogens, accounted for $60-80 \%$ in women of aged less than 25 years12-14. Other less pathogenic mycoplasma, and endogenous aerobic and anaerobic bacteria have also been implicated (15). Co-existence of sexually transmitted diseases (STD) etiological agent in genital tract predispose the women to acquisition of PID $(1,16)$. Korn et al (17) reported that clinical presentation and course of PID in women with sy,ptomatic HIV disease and/or severe immune suppression may be more aggressive than in HIV negative women.

Clinical diagnosis is rather difficult, as no single clinical and laboratory test in definite as gold standard, thus comibination of test seems to impove sensitivity and specificity $(18,19)$. Epidemiological and microbiological indices associated with PID are important source of preventable reproductive infertility in women, and other clinical squealed. Little information is available on PID epidemiology in this environment, this there is no baseline in assessment of its relationship in case of infertility and HIV infection.
Early diagnosis/treatment of PID could stemmed down the effect on the fallopian tubes; and in case of microbe-related inflammation and tubal necrosis can similarly precedes manifestation of symptoms, especially in aetiological agent due to chlamydial3. Prompt diagnosis and institution of appropriate antibiotic therapy would prevent possible sequelae of PID. The retrospective study examined the aetiological spectrum in high vaginal swabs of pelvic inflammatory diseases in this environment.

\section{MATERIALS AND METHODS}

\section{Study Site}

The retrospective study was conducted in Federal Medical Center, Nguru, between JanDec 2005, which involved the Pathology and Obsterictic/Gynecology departments. The patients folder presented at the general outpatients/gynecology clinic, with clinical complaint suggestive of pelvic inflammatory diseases, ranged from pelvic viginal discharge to lower abdominal pain, with high vaginal swabs collected and sent for bacteriological analysis. Criteria of inclusion are consecutive nonduplicate high vaginal swabs, repeated swab analysis and mixed growth of doubtful significance were excluded. Information retrieved from the patients folder included age, sex, and clinical complaint.

\section{Processing of the Specimens}

The high vaginal swab was processed, with inoculation on Blood, Chocolate and Sabouraud agar plates, incubated at $37^{\circ} \mathrm{C}$ for 24 hours. Bacterial/yeast were identified by standard bacteriogical and mycological techniques (2022). Yeats were further identified by germ tube 
test. Direct smear was prepared stained by Gram methods, and wet preparation of the specimen for parasitic examination. Antibiotic susceptibility testing was determined by disc diffussion23, using the following antibiotic discs, ofloxacin )OFX), ciprofloxacin (CPX), perfloxacin (PEF), ceftazidime (CAZ), cefuroxime $\quad(\mathrm{CXM}), \quad$ rifampicin $(\mathrm{RF})$, strepromycin(S), tetracycline (TET), trimethoprim sulthamethoxazole (SXT), anpicillin (AMP), gentamycin (CN), erythromycin (E), and augmentime(AU). The zone of inhibition of the disc was measured to determined whether resistant or sensitive in accordance to NCCLS guidelines (23). The mean susceptibility percentage of each antibiotic was calculated as the number of bacterial isolates susceptible divided by total number of bacterial isolates tested multiply by 100 .

\section{Data Analysis}

Data and information retrieved from patients flders were entered into study datavasem using SPSS version13.0. The value were expressed mean and percentage, and appropriate statistical package where necessary.

\section{RESULTS}

Of the 1350 high vaginal swabs results analyzed, $846(62.8 \%)$ were positive for 9 microorganisms by culture/or wet preparation examination (7 bacterial pathogens, 1 fungi and 1 protozoan) as in table 1 . The means age of the patient was 22.4 +2.7 years. The ratio of gram-negative bacteria ratio was 1:2:5 Monomicrobic growth was recorded in $645(76.3 \%)$, polymicrobic growth in $90(10.7 \%)$ and bacterofungal in $110(12.0 \%)$ cases. Three $(0.4 \%)$ cases yielded anaerobic growth.

Staphylococcus aureus was the accounted for 355 (41.9\%) cases, followed by Escherichia coli 190 (22.4\%), Trichomonas vaginalis 100 (11.8\%), Neisseria gonorrhoeae and Candida spp 70 (8.3\%) repetitively. Microbial-associate infection distribution, in accordance with the age group of the patients studied (tableII), frequency of occurrence was predominant with the age group 21-30 (46.7\%) and 31-40(23.9\%) years and least in $10-20(8.1 \%)$ and $>51(6.4 \%)$ years respectively. There was statistically significant difference between microbial infection and the age-group $(\mathrm{p}<0.05)$. Similarly, there was a decreasing trend pattern in frequency of occurrence of microorganism and age-group.

Antibiotic susceptibility pattern of bacterial isolates as shown in table III, showed that mean susceptibility percentage greater than 50 was observed with ofloxacin, gentamycin, ciprofloxacin, pefloxacin, rifampicin, cefuroxime, ceftazidime, erythromycin and streptomycin, and less than 50 in trimethoprimsulthamethoxazole, tetracycline, ampicillin, and augmentime. 
Table I: Frequency of occurrence of Microorganisms Isolated

Microorganisms

Gram-positive bacteria $(n=370)$

Staphylococcus aureus

Streptococcus spp.

Gram-negative bacteria $(\mathrm{n}=\mathbf{3 0 5})$

Escherichia coli

Neisseria gonorrohea

Klebsiella spp

Proteus spp.

Pseudomonas spp.

Anaerobic bacteria

Fungi $(\mathbf{n}=\mathbf{7 0})$

Candida spp

Parasites $(\mathrm{n}=\mathbf{1 0 0})$

Trichomonas vaginalis

Total
Frequency of Occurrence $(\%)$

$355(42.0)$

15 (1.8)

190(22.5)

$70(8.3)$

$30(3.6)$

$10(1.2)$

5(0.6)

$3(0.4)$

$70(8.3)$

100(11.8)

848

Table II: Distribution of bacterial isolates according to age-group of patients studied

\begin{tabular}{|cccccccccccc|}
\hline $\begin{array}{c}\text { Age- } \\
\text { group }\end{array}$ & $\begin{array}{c}\text { Sureus. } \\
\text { aureup }\end{array}$ & $\begin{array}{c}\text { KlebE.coli } \\
\text { spp }\end{array}$ & $\begin{array}{c}\text { Proteus } \\
\text { spp }\end{array}$ & $\begin{array}{c}\text { Pseud. N.gonorrhea } \\
\text { spp }\end{array}$ & $\begin{array}{c}\text { T. } \\
\text { Vaginalis }\end{array}$ & $\begin{array}{c}\text { Candida } \\
\text { spp }\end{array}$ & $\begin{array}{c}\text { Anae. } \\
\text { bact }\end{array}$ & Total \\
$\mathbf{1 0 - 2 0}$ & 30 & - & - & 10 & - & 1 & 5 & 16 & 7 & & $\mathbf{6 9}$ \\
$\mathbf{2 1 - 3 0}$ & 115 & 10 & 15 & 95 & 8 & - & 40 & 74 & 37 & 2 & $\mathbf{3 9 6}$ \\
$\mathbf{3 1 - 4 0}$ & 100 & 3 & 8 & 45 & 2 & - & 15 & 8 & 21 & 1 & $\mathbf{2 0 5}$ \\
$\mathbf{4 1 - 5 0}$ & 75 & 2 & 5 & 25 & - & 1 & 10 & 2 & 5 & - & $\mathbf{1 2 5}$ \\
$>\mathbf{5 1}$ & 35 & - & 2 & 15 & - & 3 & - & - & - & - & $\mathbf{5 5}$ \\
Total & $\mathbf{3 5 5}$ & $\mathbf{1 5}$ & $\mathbf{3 0}$ & $\mathbf{1 9 0}$ & $\mathbf{1 0}$ & $\mathbf{5}$ & $\mathbf{7 0}$ & $\mathbf{1 0 0}$ & $\mathbf{7 0}$ & $\mathbf{3}$ & $\mathbf{8 4 8}$ \\
\hline
\end{tabular}

Table III: Antibiotic susceptibility pattern of the bacterial isolates (\% susceptibility)

\begin{tabular}{|llllllllllllll|}
\hline BACTERIA & & & & & & & & & & & & \\
ISOLATES & OF & CN & CI & PE & SX & AM & RD & E & AU & S & CX & CA & TE \\
& X & & $\mathbf{P}$ & $\mathbf{F}$ & $\mathbf{T}$ & $\mathbf{P}$ & & & & & M & Z & T \\
S.aureus & $\mathbf{9 0}$ & $\mathbf{6 5}$ & $\mathbf{8 0}$ & $\mathbf{8 9}$ & $\mathbf{2 5}$ & $\mathbf{2 1}$ & $\mathbf{8 9}$ & $\mathbf{7 5}$ & $\mathbf{6 0}$ & $\mathbf{7 0}$ & $\mathbf{8 5}$ & $\mathbf{7 2}$ & $\mathbf{4 5}$ \\
E.coli & $\mathbf{8 2}$ & $\mathbf{7 0}$ & $\mathbf{7 5}$ & $\mathbf{8 3}$ & $\mathbf{4 3}$ & $\mathbf{2 6}$ & $\mathbf{7 8}$ & $\mathbf{6 5}$ & $\mathbf{7 2}$ & $\mathbf{7 3}$ & $\mathbf{7 8}$ & $\mathbf{8 0}$ & $\mathbf{5 4}$ \\
Kleb spp & $\mathbf{7 8}$ & $\mathbf{5 6}$ & $\mathbf{7 8}$ & $\mathbf{7 8}$ & $\mathbf{4 5}$ & $\mathbf{3 5}$ & $\mathbf{8 5}$ & $\mathbf{6 7}$ & $\mathbf{5 6}$ & $\mathbf{6 7}$ & $\mathbf{7 6}$ & $\mathbf{8 2}$ & $\mathbf{4 2}$ \\
Strep spp & $\mathbf{9 0}$ & $\mathbf{8 2}$ & $\mathbf{8 9}$ & $\mathbf{7 9}$ & $\mathbf{5 0}$ & $\mathbf{4 2}$ & $\mathbf{9 0}$ & $\mathbf{9 0}$ & $\mathbf{8 0}$ & $\mathbf{8 0}$ & $\mathbf{8 4}$ & $\mathbf{7 9}$ & $\mathbf{3 5}$ \\
Proteus spp & $\mathbf{7 5}$ & $\mathbf{6 7}$ & $\mathbf{7 5}$ & $\mathbf{7 4}$ & $\mathbf{3 5}$ & $\mathbf{2 2}$ & $\mathbf{7 6}$ & $\mathbf{6 9}$ & $\mathbf{6 7}$ & $\mathbf{6 7}$ & $\mathbf{7 3}$ & $\mathbf{8 0}$ & $\mathbf{4 5}$ \\
Pseudo spp & $\mathbf{6 0}$ & $\mathbf{4 2}$ & $\mathbf{7 3}$ & $\mathbf{6 7}$ & $\mathbf{2 0}$ & $\mathbf{1 2}$ & $\mathbf{6 5}$ & $\mathbf{5 2}$ & $\mathbf{4 5}$ & $\mathbf{4 5}$ & $\mathbf{7 5}$ & $\mathbf{8 2}$ & $\mathbf{3 8}$ \\
N.gonorroheae & $\mathbf{8 5}$ & $\mathbf{6 5}$ & $\mathbf{7 3}$ & $\mathbf{7 4}$ & $\mathbf{2 5}$ & $\mathbf{2 5}$ & $\mathbf{9 0}$ & $\mathbf{6 8}$ & $\mathbf{5 0}$ & $\mathbf{7 8}$ & $\mathbf{8 0}$ & $\mathbf{8 5}$ & $\mathbf{3 8}$ \\
Mean & & & & & & & & & & & & & \\
Susceptibility( & $\mathbf{8 0}$ & $\mathbf{6 3}$ & $\mathbf{7 7}$ & $\mathbf{7 7}$ & $\mathbf{3 4}$ & $\mathbf{2 6 . 1}$ & $\mathbf{8 1}$ & $\mathbf{6 9}$ & $\mathbf{6 9}$ & $\mathbf{6 8 . 6}$ & $\mathbf{7 8 . 7}$ & $\mathbf{8 0}$ & $\mathbf{4 2 . 2}$ \\
\%) & & $\mathbf{7}$ & $\mathbf{6}$ & $\mathbf{7}$ & $\mathbf{7}$ & & $\mathbf{9}$ & $\mathbf{4}$ & $\mathbf{4}$ &. & & & \\
\hline
\end{tabular}

\section{DISCUSSION}

Clinical significance of PID becomes pronounced because its association with sexually transmitted diseases/HIV/AIDS infections.
Particularly in asymptomatic individuals who may laer present with various complications irrespective of the social and psychological cost $(19,24)$. Consequently, a dramatic increase in the 
the incidence of PID has led to a parallel increase in infertility (25).

The reported prevalence of microbial-associated infection in PID of $62.8 \%$ of our patients is high. Our report is similar to the rates reported in similar studies conducted in Sokoto (26) and Gombe (27) of same geographical zone. However, comparison of PID prevalence in studies conducted at different geographical location/countries might be rather difficult, because of certain inherent biases involved, particularly presence of PID-related infections (10,28-30). Similarly, PID prevalence are influenced by variation in case definition (particularly between different clinical settings), changes in disease chronicity associated with clinically mild Chlamydia infection, variation in health seeking behaviour and increase management of PID in outpatient setting $(31,32)$.

The frequency of occurrence of microbialassociated infection was high in the age group of $21-30(46.7 \%)$ and $31-40(23.9 \%)$ years. This finding simply confirms reported findings that highest PID prevalence and highest rate of increase are associated and seen in the 16-24 years age groups, and substantial numbers of bacterial sexually transmitted infection are high these age group (16-193,6,19,33). Also PID accounts for approximately $60 \%$ of gynecological problems in women aged less than 25 years34. High prevalence of PID episodes in sexually active age group, re-emphases the correlation that co-existence of aetiological agent in the genital tract of the females predisposes to acquisition of PID (3,19,33-35). Some studies found demographic risk factors associated with
PID, like sexual activity at young age, racial, and both pre-delivery history and post-partum diagnosis of chlamdyial and gonococci infections $(36,37)$. However implication of these factors in this environment need further evaluation.

From the present study, 10 microorganism (8 bacterial pathogens, 1 fungal and 1 protozoan) were recorded. S. aureus was the commonest and accounted for $42 \%$, polymicrobial infection wasfound in $10.7 \%$ of cases and fungal infection in $13.0 \%$ of cases. This pattern simply confirms polymicrobial spectrum aetiology associated with pathogenesis of PID (11-14). S. aureus (42.0\%), and E.coli (22.5\%) were predominant bacterial isolates in the study, thesepathogens are most isolated in lower genital tract infections; and are responsible for a significant proportion of sexually transmitted diseases in Nigeria (26,38-40). The dominance of these bacterial pathogens as STI pathogens and their existence in the female genital tract clearly reaffirmed it as a predisposing factor in acquisition of PID $(1,16)$. Polymicrobial infection with other organisms such as anaerobes or faculitative aerobes may be initiated by gonorrhea, chlamydia or both $(4,5,15,35)$. The low frequency of occurrence of N.gonorrhoeae as evident in this study, might probably be due to variation in the studied population, method of microbial investigation, variation in severity of the diseases, sampling technology and site of sampling (40). Technically, $N$. gonorrhoeae is highly fastidious fragile organisms, isolation is dependent on viability of the organism in the specimen, prompt delivery to specimen, and suitability of isolation medium. 
Trichomonas vaginalis with a prevalence of $11.6 \%$ in a center posed public health problem, because of close association of trichonomasis with HIV infection (42-45). T.vaginalis, is an irritating protozoan and is a common parasitic sexually transmitted disease reported worldwide (45). It is associated with inflammation of the cervix that may mimic cervical tenderness associated with PID (42). Buve et al (43) reported that trichomonasis incidence is higher in cities where there are higher number of HIVpositive individuals. The high prevalence of trichomonasis and candiasis observed in this study basically revealed close association of poor personal hygienic conditions especially among the low socio-economic class and transmitted sexually, particularly in cases of multiple sex partners (10), with high probability of PID infection.

The in-vitro antimicrobial susceptibility pattern of bacterial isolates revealed that mean percentage susceptibility of greater than $50 \%$ was observed with the fluoroquinolones (ofloxacin, ciprofloxacin, perfloxacin), cephalosporins (ceftfazidime, cefuroxime) and rifampicin; and those less than $50 \%$ observed with gentamycin, erythromycin, augmentine and streptomycin, and least susceptibility observed in tetracycline $\quad(42.2 \%) \quad$ trimethoprimsulphamethoxazole (34.7\%) and ampicillin (2.1\%). These antibiotic susceptibility patterns are similar to reports by other workers $(26,27)$. The reduced susceptibility of antibiotics like ampicillin, tetracyclines anmd trimthoprimsulphamethoxazole, clearly revealed the abuse of these agents by self-medication practice, a common norm in most towns/cities in many developing countries.

The fluoroquinolones showed favourable in-vitro susceptibility pattern that could serve as drugs of choice in PID treatment/management. However, documented studies have reported emergence of fluoroquinolones-resistant N.gonorrheae With considerable numbers of antibiotics resistants strains, particularly of $N$. gonorrhoeae to penicillin and cephalosporins (particularly $1^{\text {st }}$ generation), the used of second-generation cephalosporins that posses extended spectrum activity over wide ranged of microorganisms associated with PID3. from the in-vitro antibiotic susceptibility pattern of the study, gentamycin, erythromycin and streptomycin, could served the antibiotic of choice considering the relative cost and also posses extended-specturm activity. One of the greater threat to the efficacy of antibiotics is the presence/or emergence of resistant strain, thus, cautious approach is required in prescription/administration, as safeguard policy against possible emergence of muliresistant strain in a remote city, like Nguru.

In conclusion, the prevalence of microbesassociated PID of $62.8 \%$, is high. It is important that microorganisms associated with PID are diagnosed early and appropriate chemotherauptic treatment/management commenced, as clinical complications are always very expensive to treat.

\section{ACKNOWLEDGEMENT}

We acknowledge the support and assistance of staff of the Pathology and Obstetric and Gynaecology departments, Federal Medical Centre, Nguru Yobe State. 


\section{REFERENCES}

1. Banikarim C, Chacko MR. Pelvic inflammatory disease in adolescents. Semin Pediatr Infec Dis 2005 16(3); 175-80

2. Crossman SH. The challenge of pelvic inflammatory disease: Am Fam Physician 2006;73 (5):859-64.

3. Burnakis TG, Hildebrandt NB. Pelvic inflammatory diseases: a review with emphasis on antimicrobial therapy. Rev Infect Dis 1986 (8) 86-116

4. Ault KA, Faro S. Pelvic inflammatory diease, Current diagnosis criteria and treatment guidelines. Postgrad Med 1993, 93 (3);85-91.

5. Ehoton-Vlasak A. Infections and infertility. Prim. Care Update Ob Gyns. 2000, 7 (5):200-206

6. Westrom L. Incidence, prevalence and trends of acute pelvic inflammatory disease and its consequence industrialized countries. Am J Obstet Gynecol 1980 138:880-92

7. Buchan H, Vessey M, Goldacre $M$ et al. Morbidity following pelvic inflammatory disease. $B r \quad J$ Obstet Gynaecol 1993; 100:558-62

8. Risch H, Howe G. Pelvic inflammatory disease and the risk of epithelial ovarian cancer. Cancer Epidemiol Biomarkers Prev 1995; 4: 447-51.

9. Cohen $\mathrm{C}$, Brunham R. Pathogensis of Chlamydia induced pelvice inflammatory diseases Sex Transm Infect 1999:75:21-4.

10. Simms Stephenson JM. Pelvic inflammatory disease epidemiology and I: what di we know and what do we need to know? Sex Transum Infect 2000, 76:80-7

11. Heinonen PK and Miettnen A. Laparoscopic study on the microbiology and severity of acute pelvic inflammatory disease. Eur $J$ Obstet Reprod Biol 1994; 57:85-90
12. soper DE,Brockwell NJ, Dalton HP, Johnson D.Observations concerning the microbial etiology of acute salphgnitis.AM J Obstet Gynecol 1994; 170: 1008-17.

13. Bevan CD, Johal BJ, Mumtaz G,Ridgway GL and Siddle NC. Clinical, laparoscopic and microbiologic findings in acute sapingitis:report on a United Kingdom cohort. Br J Obstet Gynaecol 1995;102:40714.

14. Wesrom L, Eschbenbach D. Pelvic inflammatory disease, Sexually Transmitted Diseases, KK Holmes eds. New York, McGraw Hill:783-809.

15. Eschenbach DA 1980. Epidemiology and diagnosis of acute pelvic inflammatory disease. Obstet Gynecol 55;122s-153s.

16. Mardh P. Introductory address: microbial etiology of pelvic inflammatory disease. Sex Transm Dis 1984;11(S4): 428-9

17. Korn A, Landers D. Pelvic inflammatory disease and HIV-1 infection. In :Landers D, Sweet R, eds, pelvic inflammatory disease. Pittsburgh:Springer 1999.

18. Simms I, Stephenson J.M. Mallinson H, Peeling RW, et al Risk factors associated with pelvic inflammatory diseases. Sex Transm infect 2006, 10; 1136-8.

19. Munday PE. Pelvic inflammatory diseasean evidence based approach to diagnosis. $\mathrm{J}$ Infect Dis 2000; 40 31-40

20. Chessbrough M.Medical Laboratory Maunal for Tropical Countries. English Language Books Society/Tropical Heath Technology, Butterworth 1998

21. Haley LD, and Callayway CS.Laboratory Methods in Medical Mycology. $4^{\text {th }}$ ed US Department of Heath Education and Welfare, Public Heath Service CDC Bureau of Laboratories. 
22. Cowan ST, Cowan and Steel\s Maunal for the identification of Medical bacteria. $2^{\text {nd }}$ ed Cambridge University Press, Cambridge 1985.

23. National Committee for Clinical Laboratory Standards, Performance standards for antimicrobial disc susceptibility tests. Approved standard. In; Balows A. Plot P, and Vanderpitte $\mathrm{J}$ (ed). Antimicrobial susceptibility testing. $2^{\text {nd }}$ part of Bench-level procedure manual of basic bacteriology. WHO/LAB/87.1, 1987;21-38

24. Rein DB, Kassler WJ, Irwin KL, Rabiee L.Direct medical cost of pelvic inflammatory disease and its sequelae: decreasing, but still substantial, Obstet Gynecol 2000, 95:397-402.

25. Torrington J.Pelvic inflammatory disease. J Obstet Gynecol Neonatal Nurs 1985;14(6 suppl) 21s-31s.

26. Emele FE, Anyiwo CE, and Fadahunsi AA. Etiological profile of vaginal infection in Sokoto, Nigeria. Journal of Biomedical Investigation 2004;2(2):57-62

27. Audu BM, and Kudi AA.Microbial isolates and antibiogram from endocervial swabs of patients with pelvic inflammatory disease.J Obstet Gynecol 2004;24:161-164.

28. Kwamwendo F,Forslin L,Bodin et al . programmes to reduced pelvic inflammatory disease-the Swedish experience. Lancet 1998;351:25-8

29. Simms I,catchpole M,Brugha et al Epidemiology of Gential Chlamydia trachomatis in English and Wales. Genitourin Med 1996;73:122-6

30. Hiltunen-Back E,Roostila T,Kautiainnen $\mathrm{H}$ et al. Rapid decrease of endemic gonorrhea in Finland. Sex Transm Dis 1998;25:181-6

31. Wolner-Hassen P.Silent pelvic inflammatory disease: is it overstated? Obstet Gynecol 1995;86:321-5.
32. Howard M, Doherty J, Zimic-Vicentic M, et al. An epidemiologic study of a decrease in hospitalizations of pelvic inflammatory disease (PID) in two Canadian cities (19851995). Ninth International Symposium on Human Chlamydial Infection, Napa Valley, USA 1998.

33. Suss AL, Homel P, Hammerschlag $\mathrm{M}$ and Bromberg K. Risk Factors for pelvic inflammatory disease in inner-adolescents. Sex Tramsm Dis 2000;27:289-91.

34. Simms I, Stephenson JM, Mallinson H, Peeling RW et al. Risk factors associated with pelvic inflammatory diseases. Sex Transm Infect 2006;10:1136-8.

35. Brook I. Microbiology and management of polymicrobial female genital tract infections in adolescents. J Pediatric Adolesc Gynecol 2002, 15:217-26.

36. Ness RB, Kip KE, Hillier SL, Soper DE, Stamm, Sweet RL, Rice P, Richter HE. A cluster analysis of bacterial vaginosisassociated microflora and pelvic inflammatory disease Am J Epidemiol 2005; 162:585.

37. Mahon BE, Temkit M, Wang J, Rosenman MB, Katz BP. Pelvic inflammatory diseases during the post-partum year. Infect Dis Obstet Gynecol 2005, 13(4) 191-6

38. nyemekwe CC, Meludu SC, Dioka CE, Ofor US. Pattern and distribution of sexually transmitted disease in Lagos, Nigeria. Journal of Biomedical Investigation, 2004;2(2):63-67.

39. Chikwen Jo, Ukwandu NCD, Ayuba K, and Edike MA. Evaluation of gram stained smear of urine for predicting significant bacteruria. J. Med Lab Sci 1996;5:49-53.

40. Bello CSS, Elegba OY and Dada JO. Sexually transmitted disease in Northern Nigeria: Five years experience in a 
University Teaching Hospital Clinic. $\mathrm{Br} J$ vener Dis 1983;59:202-205

41. Ilze viberga. The clinical appearance of pelvic inflammatory disease in rlation to use of intrauterine device in Lativa. Digital comprehensive summaries of Uppsala Dissertation from the faculty of Medicine 110, 2006; pg 12.

42. Moodley P, Wilkinson D, Connolly C, Moodley J, Sturm AW. Trichomonas vaginalis is associated pelvic inflammatory disease in women infected with human immunodeficiency virus. CID 2002;34:51922.

43. Dunne RL, Dunn LA, Upcroft P, O Donoghue PJ, Upcroft JA. Drug resistance in sexually transmitted protozoan

Trichomonas vaginalis Cell Res 2003;13;239-49

44. Buve A, Weiss HA, Laga M, et al. The epidemiology of trichomoniasis in women in four African cities. AIDS, 2001,15 (Supl 4): S89-96.

45. Sorvillo F, Smith L, Kerndt P, Ash L. Trichomonas vaginalis, HIV and AfricanAmericans. Emerg Infect Dis 2001;7;927-32

46. Chavalitshewinkoon-Petmitr P, Ramdja M, Kajorndechakiat S, RK, Deny WA, Wilairat P. In vitro susceptibility of Trichomonas vaginalis to AT-specific minor groove binding dugs. $J$ Antimicrob Chemother 2003;52:287-9. 